\title{
Escutando a Adolescência nas Grandes Cidades Através do Grafite
}

Listening to the adolescents through graffiti in the urban centers

Resumo: Este trabalho faz uma apreciação do fenômeno do grafite nas grandes cidades, contextualizando o protagonismo adolescente na atividade da grafitagem como uma forma de resistência aos processos de exclusão postos em prática no capitalismo.No seu decurso, descobrimos o grafite como uma ação de cidadania na qual os adolescentes, na contramão do estilo de vida que vem sendo produzido pela modernidade, conseguem engajar-se.

Palavras-Chave: Grafite, protagonismo adolescente, resistência.

Abstract: This paper makes an appreciation of the phenomenon of graphite in the big cities, contextualizing the adolescent behavior in the activity of graphiting as a way of resistance against the exclusion processes produced by capitalism. In its continuation, we discover that graphite is an action of citizenship in which adolescents, in an expression against modernity lifestyle, get to engage themselves.

Key-words: Graphite, adolescent protagonism, resistance.

Rodrigo Lages e Silva

nononojo
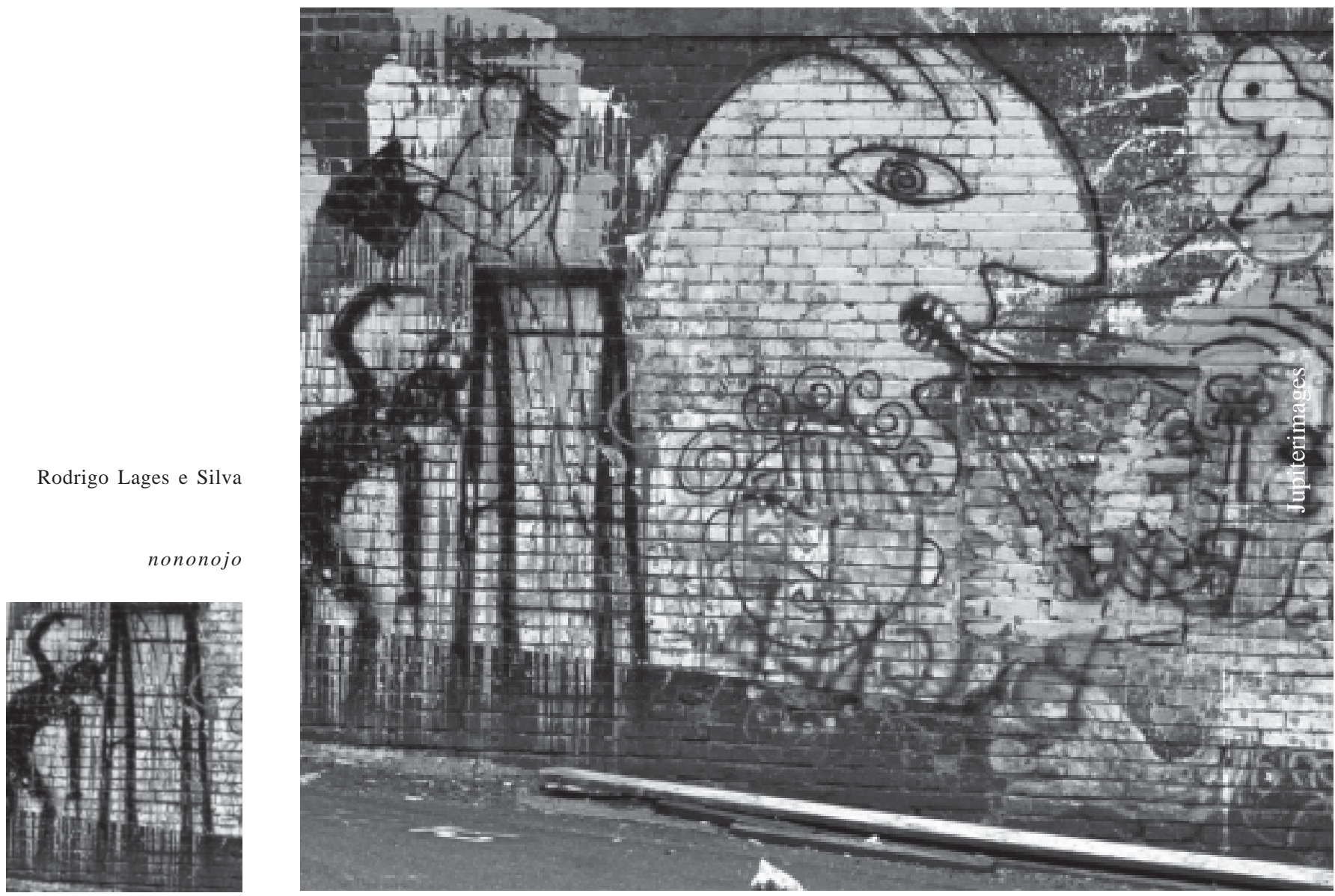

A clínica psicológica, desde a segunda metade do século passado, vem passando por um intenso processo de transformação, impulsionado, principalmente, pela gradual autonomia de sua ferramenta primordial: a escuta clínica, em relação ao seu tradicional meio de atuação: o consultório.
Como qualquer processo de incorporação de uma nova tecnologia, ou de uma nova media, é a partir da experiência que vão-se reformulando, reconstruindo ou mesmo sincretizando ( no sentido de trans-criação) os lugares teóricos que dão suporte à prática. A clínica psicológica passou, 
por isso, em cada novo meio onde foi se espraiando, não apenas impondo-se mas também mimetizando-se com cada elemento novo. Foi assim na constituição do espaço da Psicologia nas escolas, foi também assim em sua passagem pela instituição manicomial, da mesma forma vem ocorrendo nos presídios, nos ambulatórios e nos hospitais, e, em cada um desses lugares, a escuta clínica mostrou-se possível, a despeito de todas as adversidades institucionais.

Nesta monografia, trata-se de experimentá-la em um outro contexto, o do espaço urbano, principalmente aquele constituído pela rua. Também aí, acreditamos que o nosso referencial teórico se reformula e, nesse caso, o vetor dessa transformação é a sua aproximação com outras disciplinas, tais como: Semiótica, Antropologia Urbana, Ciências da Comunicação, História, Urbanismo, etc.

O primeiro choque é conjugar nossa premissa fundamental, ou seja, a escuta para além do audível, a construção de sentidos que estejam apenas parcialmente sinalizados em cada discurso, com a centralização da experiência urbana em apenas um órgão: a visão.

Trata-se de tentar encontrar um lugar para a escuta clínica dentro da nossa cultura do 'ver para crer' que, na maioria das vezes, desloca-se para um 'ver e ser visto', uma operação onde fracassa a experiência do terceiro, da mediação, da importância social desse algo em que se possa crer, uma vez que é nas crenças que compartilhamos com o outro da experiência cultural. Nesse caso, o que resta é a dualidade especular do ver e ser visto, uma redução da nossa capacidade de experimentar o novo, a diferença, já que o que se vê nesse jogo é apenas uma imagem insuficiente de si mesmo.

A cidade é, então, o palco onde, na adolescência, quando esse jogo de identificações se torna fundamental, os jovens poderão constituir algo da ordem do saber, isto é, poderão crer, acreditar em algo. Nisso, deparamo-nos com o fenômeno do grafite, e é esse o fio que vai conduzir-nos para uma ampliação da escuta clínica dos adolescentes a partir dos sentidos entre-ditos nessa produção visual marginal que é o grafite. $\mathrm{O}$ nosso meio ou meadia, agora, é a urbe e sua complicada rede de significações.

\section{Cidade como Mensagem}

Há um conceito, na teoria da comunicação, que é o da meta-linguagem. Quando um sistema de signos adquire um grau elevado de repertório, o próprio código torna-se capaz de decifrar a si mesmo. Walter Benjamim (1985) foi um dos primeiros pensadores a tentar decifrar a cidade em que vivia, nesse caso, Paris, e suas modernas passagens subterrâneas. Ainda sobre Paris, Baudelaire (1976) compôs um belíssimo poema, o Spleen de Paris, no qual a cidade se torna sua musa.

No Brasil, o grande poeta e semiólogo Décio Pignatari (1995), fundador do concretismo com os irmãos Augusto e Haroldo de Campos, escreveu um brilhante artigo intitulado Semioticidade, no qual propõe: “A cidade é uma mensagem que nem todos entendem, mas que todos são obrigados a ler” (p.205).

Admitindo que a cidade seja uma mensagem, ainda nos resta a pergunta: "Quem escreve e quem lê a cidade?” Para buscar essa resposta, podemos aproveitar um conceito de Jean Baudrillard (1976), que propõe considerar a arquitetura e o urbanismo como mídia de massa. Sob o prisma da afirmação de Pignatari, de que a cidade é um signo-objeto, podemos concluir que a cidade é a mensagem e o seu meio (ou mídia) fundidos, ou seja, a cidade faz uma síntese na dicotomia entre forma e conteúdo, como nos diz Lefebreve apud Ruiz (1999): “o urbano como cenário de uma curiosa independência entre a lógica da forma e a dialética dos conteúdos” (p.18).

Retomando a pergunta inicial, deparamo-nos com o fato de que a cidade é construída segundo os interesses da parcela da população que é capaz de fazer valer seus desejos, em especial quando se trata da parcela economicamente mais privilegiada.

Pignatari vai adiante em seu artigo, no sentido de tentar responder à pergunta que ele mesmo se faz. Propõe duas maneiras de se relacionar com o espaço urbano. A primeira delas, algo que chama de usuariedade, é justamente produto da alienação que o capitalismo impõe, sobre a qual nos aprofundaremos mais adiante, entre o objeto de desejo e o meio para acessá-lo.

A esse respeito, gostaríamos de propor uma metáfora. Essa alienação faz com que a cidade pareça o desenho de M.C. Escher: House of Stairs, 1957. À primeira vista, é possível imaginar-se subindo e descendo todas as escadas que ligam os diversos pavimentos, que, entretanto, se encontram no mesmo nível. É como se a perspectiva (que nos apresenta o objeto de desejo) fosse perfeita, mas a geometria (que nos dá o acesso) fosse impossível. Por isso, a usuariedade torna-se um último recurso, onde o usuário da cidade "só consegue ler a cidade na prática metonímica da sobrevivência de curto prazo” (Pignatari, 1995, p.206). 
Paul Valéry dizia que há arquiteturas que são mudas, outras que falam, outras, ainda, que cantam. Permanece muda a cidade que não estabelece o diálogo entre a urbe e a polis; começa a falar a cidade que estabelece esse diálogo - e começa a cantar a cidade onde os urbanitas se elevam ao nível de cidadãos, em coro com o gerenteregente; Freiheit! Freude!

Pignatari
Por outro lado, o autor reconhece uma outra forma de relacionar-se com a cidade e que ele chama de comunitária. Nesta, o cidadão estabelece um diálogo com a urbe, isto é, busca entender o que a cidade fala e, em contrapartida, fazer reverberar o que ele tem para dizer. É justamente aí que reconhecemos o grafite. Como veremos adiante, ele introduz profundidades inimagináveis na cidade, questionando a linearidade do traçado. O grafite é uma forma de apropriação da cidade como matéria-prima. O grafiteiro modifica a urbe através de uma atitude enunciativa. Instaura a metáfora urbana onde antes só era possível a linearidade, uma vivência metonímica de moverse no labirinto urbano, sem reconhecer de que matéria a urbe é feita. O grafite não é apenas uma prática comunitária, mas um exercício de cidadania.

Paul Valéry dizia que há arquiteturas que são mudas, outras que falam, outras, ainda, que cantam. Permanece muda a cidade que não estabelece o diálogo entre a urbe e a polis; começa a falar a cidade que estabelece esse diálogo - e começa a cantar a cidade onde os urbanitas se elevam ao nível de cidadãos, em coro com o gerente-regente; Freiheit! Freude! (Pignatari, 1995, p.207).

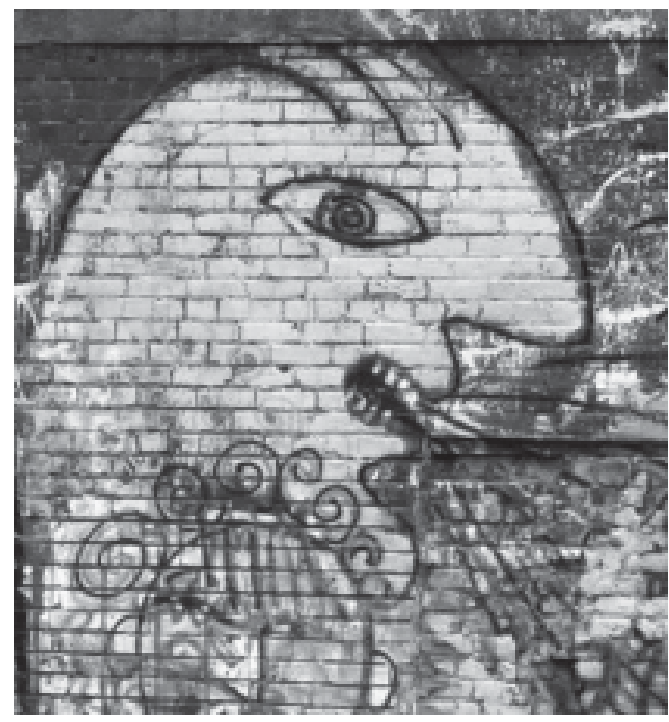

\section{Grafite}

Um primeiro problema para qualquer teorização que se venha a fazer sobre o grafite é o da definição do que pode ser considerado um grafite. A raiz etimológica: graffiti, donde deriva a tradução grafito (inscrição ou desenho de épocas antigas, toscamente riscado a ponta ou a carvão em rochas, paredes, vasos, etc, segundo o dicionário Aurélio), não nos ajuda muito. Porém, a comparação entre o grafite, tal qual nós o encontramos hoje, e os grafitos com os quais os primeiros arqueólogos se depararam, pode ser assaz interessante. Em primeiro lugar, porque a nossa reação enquanto pesquisadores, nos dois casos, pode, seguramente, ser a de espanto. Afinal, o grafite, assim como os grafitos, denuncia a existência de uma outra ordem, uma existência em um outro lugar, certamente, mas também em um outro tempo, seja ele contado em séculos, ou no tempo de uma operação subjetiva que pode estar implicada no intermezzo entre infância e maturidade. Em segundo lugar, porque o paradigma indiciário, com o qual os arqueólogos estão, desde há muito tempo, acostumados, nos serve igualmente para a análise do grafite, uma vez que ele também marca uma passagem, isto é, representa alguém, no caso um jovem grafiteiro, em sua ausência, ou em sua invisibilidade, já que, "para o filósofo natural, como para o filólogo, o texto é uma entidade profunda invisível, a ser reconstruída para além dos dados sensíveis” (Ginzburg, 1989, p.158).

Podemos abordar o grafite de um ponto de vista metonímico, de sua tradução em linguagem verbopictórica para nosso estreito código gutemberguiano, isto é, de pensar em que essa linha contínua poderia dizer em termos do caractere digital de um teclado. Em outras palavras: o que se diz no grafite? E podemos, igualmente, abordá-lo de uma perspectiva metafórica, ou seja, sobre quem fala o grafite? Que tipo de impressão me causa esse grafite, que transforma alguns conceitos que trago comigo sobre a minha cidade e sobre a juventude que habita o meu bairro, e que outrora habitou meu corpo ?

De um modo geral, a grande diferença dessas duas perspectivas é que uma busca reconstruir o passado para explicar um evento presente, a outra toma esse evento presente como ponto de partida para uma problematização do futuro. Nosso propósito, nesta monografia, passa, certamente, por essas duas experiências. Em parte, cabe-nos a diferenciação e a categorização do que seja um grafite, buscar, em algum princípio elementar, os critérios para poder distinguir o grafite da pichação e do tag, não nos furtando, porém, de observar alguns elementos presentes no grafite e que podem ser descritos como parte de uma estética particular da qual é possível rastrear a raiz histórico-social, por exemplo, o kitsch; de outra parte, o nosso olhar vem sendo pautado, em grande parte, e, inevitavelmente, continuará sendo, pela preocupação em tentar ler uma nova saída para a questão da adolescência marginalizada, uma saída para o problema subjetivo que se impõe ao jovem que tenta, hoje, integrar-se a uma sociedade marcada por desigualdades e por uma lógica excludente; saída artística enunciativa/denunciativa, na qual o adolescente transforma a sua realidade e a nossa, seguramente. 


\section{Grafite, Pichação e Tag}

Sempre que falamos em grafite, evocamos a lembrança da pichação. Por vezes, parece que a pichação é o duplo do grafite, sua sombra, 'o lado negro da força'. Enquanto estamos mais aptos a admitir que o grafite pode ser uma 'espécie' de arte ou de expressão cultural, nosso impulso higienista e legalista está sempre nos inclinando a tratar da pichação como vandalismo. Nosso esforço será, entretanto, o de demonstrar que essa diferenciação pode deixar-nos um pouco mais tranqüilos diante das transformações que ambos, sem dúvida, provocam na paisagem urbana. Esta, no entanto, possui muito pouco de verdadeira. Inclusive, é para nós também surpreendente que os próprios grafiteiros não saibam diferenciar exatamente o que seja uma pichação de um grafite. Eles têm, contudo, uma certeza: o grafite não é uma evolução da pichação, como os administradores das grandes cidades gostariam que fosse. Ambas as práticas podem coexistir em uma cidade ou em um bairro, ou, ainda, na mesma pessoa. Muitos grafiteiros são também pichadores.

Em geral, a diferenciação mais óbvia é um posicionamento do grafite mais próximo do campo da pintura e a pichação, mais para a escrita. Ocorre, entretanto, na prática, uma mescla tão grande, ou seja, grafites que se expressam verbalmente e pichações que 'deformam' a letra até que ela assuma uma imagem totalmente nova, ficando impossível diferenciá-los apenas por esse critério.

Essa dificuldade pode fazer com que imaginemos que haja uma diferença entre a ação dos grafiteiros e a ação dos pichadores em relação à justiça. Não é verdade, pois, "aos olhos da justiça”, o grafiteiro pode ser tão ‘vândalo’ quanto o pichador. Grande parte dos grafites são inscritos/pintados à noite, clandestinamente; muitos ainda ficam pela metade quando a polícia chega. Tampouco podemos usar como critério diferenciativo a qualidade e a elaboração do traço. Podemos encontrar grafites muito simples. Afinal, como qualquer outra prática, o grafite tem seus iniciantes e pichações muito elaboradas.

A despeito de toda a proximidade dessas duas ações, acreditamos que elas mereçam ser categorizadas distintamente, na medida em que possuem diferenças que, mesmo não podendo ser muito apreciáveis em seu resultado final, são relativas ao desejo. Existem, certamente, lugares diferentes para Outro na pichação e no grafite. De saída, podemos apontar as distintas formas de se referirem à lei. Enquanto a pichação busca o declínio da lei, tenta surpreendê-la onde ela talvez não alcance, lá em cima, bem lá em cima ('como alguém conseguiu chegar até lá para pichar?’), o grafite tenta argumentar com a lei, criar jurisprudência no direito à autoria na paisagem urbana enquanto arte de rua. O grafite provoca o questionamento sobre os limites de nossa apropriação da cidade, ('se a propaganda pode tomar todos os muros, todos os lugares, porque os cidadãos não podem pintá-los?’). As pichações costumam buscar denegrir o local onde são feitas. Zombam da indiferença das estátuas, da ineficácia dos prédios públicos. O grafite busca criar profundidades nas superfícies planas da cidade. Busca transformar nossa maneira de enxergar.

Ver mais não é apenas ver mais longe, para além dos limites das nossas paredes e horizontes presentes. É desenvolver uma nova precisão e flexibilidade do nosso olhar; é ver por trás das nossas costas, como vemos à frente dos olhos; é apreender o mundo não apenas numa relação frontal, mas num ambiente circunstância é multiplicar as facetas dos nossos olhos e os objetos do nosso olhar simultâneo como se todas as câmaras do mundo fossem a realização de um novo Argus (Kerckove, 1997, p.27).

Além disso, a própria dinâmica subjetiva que pode culminar em uma pichação ou em um grafite é diferente. A pich-ação é muito mais impulso, actingout. Costuma ser feita e pensada no calor do momento. Já um grafite, normalmente, passa por um longo processo de desenvolvimento nos cadernos (todo grafiteiro tem o seu) antes de ir para um muro.

Ambos, grafite e pichação, podem ser considerados como recursos da linguagem, no sentido de tentar gravar sinais de referência em uma cidade que tende a reduplicar infinitamente a sua paisagem, processo pelo qual o sujeito deixa no exterior as marcas da transformação subepidérmica que o acompanha, declarando limites para evitar a psicastenia e, com isso, completar a formação de sua identidade (Olalquiaga, 1998, p.25).

Como elementos de linguagem, ambos são efeitos de uma tendência do código (língua) para tornarse cada vez mais sintético. A comunicação vem em uma linha evolutiva que aponta para a instantaneidade, para a iconografia, para a visualidade e para a economia. É o tempo do slogan, da logomarca e da poesia rápida (daí a total modernidade do haikai), porque todos temos pressa, e o que deve ser dito tem que ser breve, quase instantâneo, senão corre forte risco de não ser ouvido. A pichação nos fornece os melhores exemplos no campo do sintagma, ou seja, da estrutura: SK8 (skaite), K-B-ça (cabeça) e outros
"Ver mais não é apenas ver mais longe, para além dos limites das nossas paredes e horizontes presentes. É desenvolver uma nova precisão $e$ flexibilidade do nosso olhar; é ver por trás das nossas costas, como vemos à frente dos olhos; é apreender o mundo não apenas numa relação frontal, mas num ambiente circunstância é multiplicar as facetas dos nossos olhos e os objetos do nosso olhar simultâneo como se todas as câmaras do mundo fossem a realização de um novo Argus “.

Kerckove 
tantos, enquanto o grafite realiza, de forma mais inequívoca, o princípio da visualidade. Ambos são efeitos dessa lógica e fazem-nos refletir sobre os limites do campo pictórico com o verbal.

Porém o tag, certamente, é o elemento que nos deixa mais intrigados quanto à sua inclusão em uma dessas duas categorias, pintura ou escrita, grafite ou pichação. Tag é como se chama, na publicidade, a etiqueta de determinada marca. É um desdobramento da logomarca que serve para ser fixado nos produtos. A cultura paródica, sobre a qual nos aprofundaremos adiante, denuncia como a arte e a publicidade têm andado juntas Na sua apropriação pelos grafiteiros e pichadores, podemos afirmar que o tag é algo que se situa do ponto de vista da paródia da arte, porque, em parte, tanto o grafite quanto a pichação fazem uma apropriação crítico/criativa do campo artístico: uma assinatura. Do ponto de vista de uma paródia da publicidade, supostamente oferecendo algo que eles não têm pra vender, ou seja, uma identidade, o tag é uma logomarca.

Então, o tag é essa assinatura que deve inserir o sujeito, ao mesmo tempo, em dois registros: o registro formal, enquanto produtor de linguagem, ou seja, enquanto autor, e o registro do comércio, enquanto produto da sociedade de consumo, sujeito consumidor/consumido, pois, de fato, o estilo de vida normal, hoje, é o de consumir produtos que nos constituam simbolicamente mas também o de produzir cultura, tornando-se o próprio objeto de consumo, tendo uma imagem a ser copiada, um estilo. Nessa medida, como afirma Sordi (1997), o desenho é um espaço onde se trabalha a corporeidade e serve para construir a subjetividade. A escritura do nome, através do assinar, representaria, portanto, um novo espaço para trabalhar a subjetividade, ou, nas palavras de Manuel Delgado Ruiz (1999):

Este é, em última instância o valor do tag, simples assinatura, mas também grito gráfico de 'Existo!'; sinal pessoal indicativo do trânsito do autor por um local determinado, que passa a ser lugar- quer dizer nicho de memória e de sentido - a partir desta mesma apropriação da celebração e do ritual que é estampar a própria assinatura sobre o texto em branco de um ponto elementar da metrópolis (p.125).

Grafiteiros e pichadores possuem o seu tag, mas arriscamos a hipótese de que o princípio do tag se aproxima mais do grafite. Podemos dizer que se trata de uma afinidade alegórica no sentido de que o grafite, como alegoria, pode ser considerado uma saída alternativa para a impossibilidade radical de que o simbólico represente o real sem nenhuma perda (dirão os lacanianos que $a$-lgo sempre escapa), isto é, como é impossível dizer unicamente através de símbolos ou da escrita tudo aquilo que é o problema de ser adolescente nesta cultura, os grafiteiros fazem o imaginário incidir sobre o simbólico, de certa forma, compensando essa impossibilidade.

A perda que toda inclusão na escrita implica é a da letra enquanto imagem. Não conseguimos mais olhar qualquer letra que seja sem concebê-la a partir de sua relação com o restante do alfabeto. A letra perde seu corpo e passa a responder apenas quanto à sua função.

De certa forma, assim como a letra perde sua imagem, o adolescente, ao incorporar-se ao social, perde também a imagem idealizada do seu corpo, ou seja, passa a integrar o mundo dos normais, o que quer dizer um mundo bem distante da perfeição ideal. Então o tag, nesse período de transição, pode ajudar a que alguma parte dessa imagem idealizada sobreviva, nem que o faça a partir da alegorização da assinatura, isto é, criando uma marca, algo que o valorize imaginariamente entre os outros, pois o tag resgata a imagem da letra, ao mesmo tempo em que denuncia a impossibilidade da palavra em dizer tudo aquilo que se queria.

\section{Grafite e Ação de Rua}

Para podermos falar do grafite como ação de rua, é necessário que tenhamos clara a noção de que, no contexto da cidade, tal qual estamos trabalhando, o espaço não é só um suporte para a criação, mas é também a matéria-prima da criação. A rua não é apenas uma exterioridade na qual a suposta interioridade do psiquismo pode vir a se expressar em manifestações como o grafite, mas é também o paradigma de uma apropriação que se faz necessária para todo adolescente, como forma de realizar a passagem do ambiente caseiro e familiar para um ambiente mais social e exterior, e da reivindicação do seu quinhão no patrimônio público, maneira pela qual o sujeito passa a exercer sua autonomia, pois, como afirma Boada (1991), "a conquista do espaço externo para nós mesmos dar-se-ia quando fosse uma conquista de nós mesmos naquele espaço, isto é, um desenvolvimento de nosso processo de realização" (p.18).

Esse desafio quanto aos problemas singulares que se colocam ao adolescente, relativos à sua integração à massa de sujeitos que constituem o social, pode materializar-se na condição da rua. A rua pode vir a ser um local onde nada é possível, o local da exclusão ou da incorporação forçada aos padrões vigentes. Então, o espaço privado e protegido da casa pode tornar-se um refúgio para 
os adolescentes que não se sentem capazes de enfrentar toda a pressão do convívio público, daí o refúgio em atividades de lazer e entretenimento (TV , video-games, etc), fazendo com que os grupos juvenis recentes se caracterizem por uma busca de intensidade no lazer em contraposição a um cotidiano que se anuncia como "medíocre e insatisfatório":

Caracterizada como imobilizada pela indústria cultural e, ainda, marcada por um longo período autoritário, essa juventude é descrita como limitada a um posicionamento individualista que não apenas impediria uma visão crítica da sociedade como também impossibilitaria a formulação de qualquer projeto de mudança social por parte desse segmento (Herschmann, 2000, p.55).

O adultescer provável de uma juventude limitada a esse campo de experiência é aquele que vemos multiplicar-se por todos os lados, de pessoas que passam a experimentar o público através de intermediários (ou intermidiários), por meio de novelas, revistas ou todo tipo de mídia de massa que, trabalhando a um nível baixo de repertório como deve ser toda mídia de massa por princípiooferecem poucas surpresas e poucos riscos. Esse tipo de proteção, no entanto, é também uma exclusão, qual seja, a exclusão no nível da produção cultural. “A figura atual de uma marginalidade não é mais de pequenos grupos, mas uma marginalidade de massa; atividade cultural dos não produtores de cultura...” (Certeau, 1994, p.44). O resultado disso é também uma restrição do nosso espectro de referências. Cada vez mais, temos menos diversidade e mais homogeneidade.

Vivemos hoje um mundo em que meia dúzia de imagens parecem ser suficientes para saciar nossa sede de vida e nos entreter nesse movimento embriagado que vai dos shopping centers aos best sellers de auto-ajuda. Muitos escritos podem vir a cumprir a função de resistência. Resistência em dois sentidos: resistem à pasteurização da experiência e também resistem ao leitor obrigandoo a um esforço de encontrar para si um outro lugar discursivo (Souza, 1998, p.29).

Então, o grafite, podemos dizer, é um desses escritos que resistem à homogeneização, que são não apenas enunciações, mas, sobretudo, engajamento. Aliás, se o próprio exercício afirmativo é algo raro em tempos pós-modernos, é ainda menos freqüente, e há algo de muito depressivo nisso, a adesão e o engajamento em alguma ação. "Campo e cidade - e não somente sindicatos e universidades - são povoados silenciosos. Não por carecerem de idéias e de discernimento! Mas suas convicções não constituem adesões" (Certeau, 1995, p.32). Por isso, devemos poder distinguir o que é um acontecimento eventual, ou seja, aquilo que faz parte de uma linearidade de acontecimentos marcada pela ordem das coisas existentes, daquilo que é uma atuação, ou ainda, do que podemos considerar ação ou protagonismo.

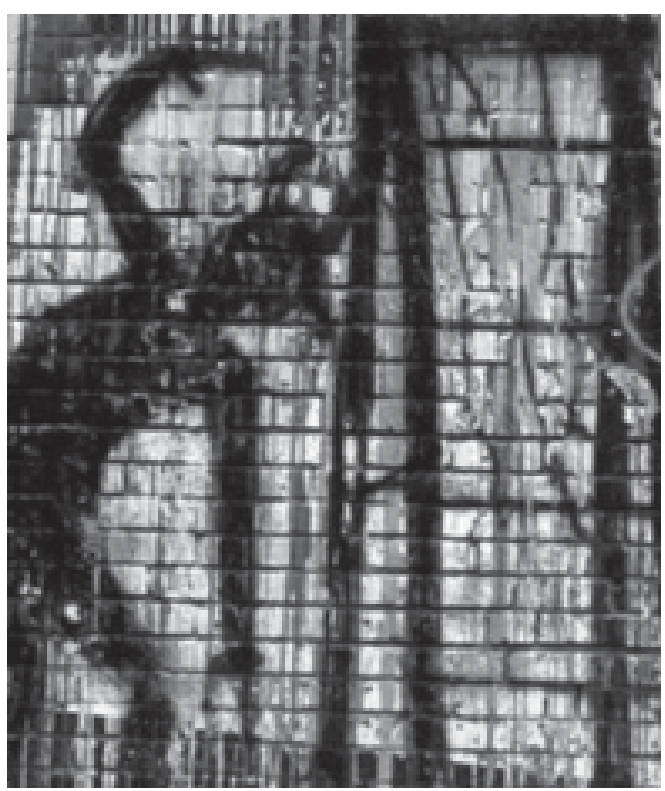

Harendt (1994) propôs que aquilo que difere uma ação de um acontecimento é que a primeira busca intervir no curso da História. É impossível falar do grafite sem observar que ele surge num contexto urbano particular, com a explícita determinação de provocar uma mudança no curso evolutivo da cidade. Ainda que não seja um acting-out (uma atuação naquele contexto talvez pejorativo com o qual a Psicologia define um assujeitamento da pessoa a motivações que ela mesma não é capaz de controlar), o grafite pode ser considerado uma ação no sentido do protagonismo, dentro de uma cultura marcada pela espetacularidade.

Então, essa forma de protagonismo social que caracteriza o grafite deve ser diferenciada do que foi, por exemplo, a atuação social da juventude de maio de 68, que começou a inscrever suas palavras de ordem pelas ruas de Paris, principalmente porque o grafite não tem palavras de ordem. Podemos dizer que a inovação do grafite é a sua forma, e não seu conteúdo. O discurso político diz coisas diferentes, mas sempre da mesma forma, e o discurso revolucionário pode não dizer nada de novo, mas o faz de forma surpreendente. Como nos sugere Lukács, apud Leminski (1995), o que há de revolucionário na linguagem é a sua forma, não o seu conteúdo, pois os grafiteiros não estão a dizer nada diferente. Ao contrário da juventude dos anos 60 e 70 , que tinham um
Este é, em última instância o valor do tag, simples assinatura, mas também grito gráfico de 'Existo!'; sinal pessoal indicativo do trânsito do autor por um local determinado, que passa a ser lugarquer dizer nicho de memória e de sentido - a partir desta mesma apropriação da celebração e do ritual que é estampar a própria assinatura sobre o texto em branco de um ponto elementar da metrópolis 
projeto político-ideológico, a juventude que se agrupa em torno do grafite o faz porque consegue, assim, experimentar uma coletividade, uma ‘tribalização', a partir da experiência de compartilhar um saber prático que é o de colorir as ruas da cidade. "Essas práticas colocam em jogo uma ratio 'popular', uma maneira de pensar investida numa maneira de agir, uma arte de combinar indissociável de uma arte de utilizar” (Certeau, 1994, p.42).

\section{Grafite, Kitsch e Cultura Paródica}

Por tudo o que já pudemos ver, o grafite é um fenômeno intimamente ligado ao marketing e à publicidade. De um modo geral, toda a produção artística atual é influenciada, em maior ou menor grau, pelo capitalismo de consumo, mas, ao contrário de outras expressões artísticas que passaram a adotar os padrões ditados pela indústria da arte 'pura e simplesmente', acreditamos que o grafite pode ser considerado um efeito colateral da arte de consumo. Manuel Delgado Ruiz (1999) vai falar abrangentemente em uma cultura paródica para tentar definir a forma pela qual os adolescentes incorporaram os padrões do capitalismo de consumo e o modificaram no interior de seu próprio processo de amadurecimento e busca de identificações, para, em seguida, revertê-lo ao exterior a partir de manifestações artístico-culturais, dentre elas o grafite, manifestações que se constituem corruptelas do modelo vigente de arte de massa. Acreditamos que esse seja, essencialmente, o princípio do kitsch, e vamos tentar identificar suas origens.

Pignatari (1970) faz uma conceitualização do kitsch a partir da teoria da informação, na qual o kitsch passa a corresponder a uma tentativa de tradução da informação elitizada e de alto repertório, por parte das camadas populares, a partir de seu repertório mais restrito de signos. Dessa forma, o kitsch é sempre a versão popular de um objeto valioso. Essa passagem do objeto-coisa, do objeto em si, para o objeto-representação, o objeto signo, faz com que o kitsch seja, para Pignatari, o representante máximo do processo de semiose.

Desde que passamos do capitalismo de produção para o capitalismo de consumo, aquilo que dá valor a alguém na sociedade deixa de ser aquilo que ela faz, ou seja, o que ela produz para o social, mas o que ela consome. Então, nesse processo, as camadas populares também começam a reivindicar para si a possibilidade de incorporarem-se ao grupo das pessoas que têm poder de consumo, e a indústria também passa a perceber a camada pobre como consumidora em potencial. Nesse movimento, a arte ou a cultura são igualmente alvos do impulso comercial, que vem abarcando todos os objetos potencialmente vendáveis.
Ocorre, entretanto, com a exacerbação do consumo em todas as suas áreas, que o kitsch deixa de ser um efeito apenas das camadas populares, mas a classe alta também começa a copiar as modas ditadas pela maioria, que agora não é mais a maioria rica, mas a maioria pobre. Então, temos o fenômeno de 'patricinhas' subindo o morro em busca de bailes funk e de 'mauricinhos' tocando pagode em alto e 'bom' som em seus carros importados. Daí podermos dizer que, enquanto a vanguarda é o novo no nível da produção, o kitsch é o novo no nível do consumo. "No nível da linguagem, kitsch e vanguarda encontram seus mais importantes pontos de contato naquilo que têm de processo primitivo, básico, de crítica e criação de signos...” (Pignatari, 1970, p.117).

Por outro lado, os processos de significação, assim como os de identificação, são fadados, desde já, ao fracasso, pois, como já apontamos, o signo, mesmo o signo novo como pode ser o kitsch no nível do consumo, nunca é suficiente para saciar toda a sede contínua e ininterrupta de significado que o 'existir' demanda. Por isso, acreditamos que o grafite, enquanto cultura popular, situa-se a meio caminho entre a estética kitsch e a alegoria, pois há, na alegoria, o exercício de fundar, a partir da imagem (da metáfora), uma alternativa à impossibilidade semiótica, ou de significação.

Acreditamos que esse meio caminho entre kitsch e alegoria é o que podemos considerar, de fato, cultura paródica, resgatando a idéia de Ruiz. Então, o grafite seria uma paródia da arte de elite, ao mesmo tempo em que uma paródia da publicidade, uma vez que faz uma apropriação de uma arte mural, não uma apropriação 'tal e qual', mas uma apropriação crítica, pois aponta os limites da arte muralista. Faz, também, uma apropriação criativa, enquanto busca a emergência de um elemento novo, não no nível da técnica ou da produção, pois, assim, seria arte de vanguarda, mas da sua imposição como arte de consumo, parafraseando os cartazes publicitários. "Dos cartazes aos grafites, a relação entre a oferta e a demanda se inverte....” (Certeau, 1995, p.46).

\section{Metrôs, Muros e Galerias ou à Guisa de Conclusão}

O caminho, para tentarmos construir algo de conclusivo sobre o grafite, tanto em relação ao seu lugar dentro da dinâmica adolescente quanto em relação à sua presença massiva nas grandes cidades, passa, necessariamente, pelo questionamento do que é tornar-se adulto.

Calligaris (2000) propõe que alguém pode considerar-se adulto quando atinge a condição de ser desejado e invejado. Então, o que podemos 
deduzir disso é que a condição de adulto é algo que nos é dado pelo Outro, uma vez que é dele que nos vem esse reconhecimento. Vamos tentar, agora, compreender o grafite à luz dessa noção.

O grafite surge em Nova Iorque no final dos anos 80, inicialmente desenhado nos metrôs. Antes disso, já existiam as pichações ideológicas dos estudantes franceses, isso por volta de maio de 68 . Caetano Veloso inspirou-se numa dessas pichações para compor É proibido proibir. No entanto, é certo que, do fim dos anos 60 ao fim dos anos 70 , houve mudança na condição juvenil, e acreditamos que essa mudança seja o mote do esvaziamento ideológico pelo qual passaram as primeiras pichações até a constituição do grafite.

Calligaris faz a interessante observação que o ideal dos adolescentes dos anos 60 era o de tornaremse adultos. "O desejo era não de se conformar aos adultos, mas de não se diferenciar deles por serem infantis, adolescentes” (p.71). Nesse contexto, não surpreende que a pichação tivesse uma natureza mais formal, com mais conteúdo. Havia a necessidade de um convencimento: 'vejam só, eu também sei algo, também posso pertencer a este mundo'.

A cidade ainda era uma cidade do trabalho, da produção. Naquela época, as ruas levavam a algum lugar. As pessoas tinham aonde ir. A cidade era o ponto de convergência das vontades e dos projetos, era onde o 'sonho' poderia concretizar-se.

Muito rapidamente, as coisas tomaram outros rumos. O ápice do potencial produtivo fabril superou a demanda, ao passo que a singularidade e a individualidade tornaram-se o paradigma das relações sociais. Os adolescentes, que outrora acreditavam em uma saída coletiva, passaram a perseguir obstinadamente alguma marca distintiva. Nesse contexto, a sociedade organiza-se simbolicamente em torno do consumo, de modo que a cidade também sofre um deslocamento. A cidade deve ser usufruída. Há não só uma exacerbação do lazer e do entretenimento individuais, centralizados nas experiências solitárias de consumo, mas também moradia e circulação passam a constituir signos distintivos. As pessoas não têm mais para onde ir, uma vez que deslocarse deixa de ser algo da ordem do dever para tornarse uma questão de desejo. O automóvel, certamente, caracteriza um signo distintivo deveras importante dentro desse contexto.

Nesse período é que o processo de alargamento das periferias começa a chegar a um ponto de estrangulamento. A mudança no perfil da cidade corresponde à mudança no conceito de trabalho. Há uma desvalorização do trabalho concomitante a uma supervalorização do lazer, processos que, sem dúvida, estão relacionados com a frustração das utopias coletivas.

Agora, então, falta apenas uma condição para uma virada no ideal social. A prerrogativa do sexo, que antes era algo exclusivo da vida adulta, depois da premissa do 'amor livre' da geração sessentista passa a ser um privilégio também dos adolescentes, mas ainda melhor, porque não precisam fazer coincidir, necessariamente, a realização sexual com o matrimônio. O resultado disso é que, se antes o bom era ser adulto e poder compartilhar do bônus da vida adulta- sexo (ser desejado) e trabalho (ser invejado)- agora o ideal é ser adolescente e poder praticar o sexo livremente e o lazer ininterrupto, sem toda a carga do trabalho. Os adultos também querem ser adolescentes.

A pichação, agora, não sabe mais nada, não é a partir do saber que é possível estabelecer um laço social. Então, é na experiência do grupo, em uma nova 'tribalização', como já apontamos, que essa moratória social pode ser suportada, pois foram os metrôs que, inicialmente, deram suporte a essas novas inscrições, com grafites que buscavam apenas informar a existência, em determinado lugar, de alguém ou de um grupo.

Na circulação dos metrôs pela cidade, fica representada, de forma pungente, esse sem-lugar que a modernidade produziu. O metrô é, ao mesmo tempo, símbolo máximo do transporte urbano de massa, cobrindo enormes distâncias em pouco tempo, e elemento imprescindível à formação das periferias.

Do metrô para o muro, a juventude realiza o segundo momento de uma apropriação do tempo para uma apropriação do espaço. O que se toma do Outro não é mais o momento de um olhar, uma passagem do freiar do trem até o bip das portas se fechando. Agora, o que se toma do Outro é o seu próprio movimento, são eles que param e, com isso, os grafiteiros ganham todo o espaço que eles ainda não trilharam. Quando se consegue capturar o olhar, ainda que por um tempo pequeno, quando esse Outro pára para ver, ele não recomeça a andar pelo mesmo caminho. Esse espaço foi conquistado. O grafite torna-se, assim, instrumento de transformação do cotidiano.

O que mais falta conquistar? Há, ainda, um outro espaço que não pode mais ser tomado de ninguém, mas que é adquirido por merecimento, um espaço que é oferecido pelo Outro. Há algo no muro que, em algum momento da vida de um grafiteiro, pode tornar-se inconveniente. Em primeiro lugar, porque ele descasca. Um grafite é sempre efêmero; em segundo lugar, porque, como a maioria das coisas
O caminho, para tentarmos construir algo de conclusivo sobre o grafite, tanto em relação ao seu lugar dentro da dinâmica adolescente quanto em relação à sua presença massiva nas grandes cidades, passa, necessariamente, pelo questionamento do que é tornar-se adulto. 
que é tomada por apropriação, ela pode ser retomada. Então, um grafite, sobre um grafite, sobre outro grafite... Até quando essa grupalidade é confortável? Até quando dura uma adolescência? É fato que ser adulto é uma garantia que não se tem facilmente; lembrem-se daquela história de ser desejado e invejado. No entanto, também é certo que não é possível suportar, por muito tempo, as identidades grupais. Então, sobreviver simbolicamente, criar coisas que ultrapassem o perecimento do corpo, torna-se necessário.

\section{Grafiteiro ou Artista?}

A resposta pode começar pela compreensão que o desafio do artista é sempre o de preencher o branco da tela ou do muro, se ele for muralista. O grafiteiro, entretanto, precisa do branco. Ele é sua assinatura imaginária, é a sua borda, o seu limite. Qual seria a validade de expor sua marca se ela ficar dissolvida no mosaico de todas as outras marcas de todos os outros adolescentes? Afinal, não é disso que sofremos na modernidade, da indiferenciação na multidão? Como poderemos ser todos artistas de cinema?
O grafiteiro artista de rua milita a favor da arte de rua, mas, em algum momento, ele pode ver-se compelido a lutar pela sua arte. Então, a nossa hipótese é que o branco do muro pode ser substituído por outras bordas, outros limites. O grafite rompe com o anonimato da existência, mas não resolve a questão do anonimato do fazer. Um grafiteiro nunca poderá ser como um muralista de academia porque suas trajetórias são diferentes. Isso não significa, entretanto, que ele não possa fazer arte mural. É possível fazer arte de galeria e arte de rua, assim como também é possível fazer pichação e fazer grafite.

Cabe aos jovens grafiteiros, então, o desafio de não cair em identidades estanques e de se permitirem a circulação por outras mídias. O meio, media, transforma o resultado final da arte, e todo o lançar-se em algo novo implica uma perda. Muitos dos que já foram jovens preferem, hoje, a segurança do interior de seus muros. Agora, podemos acreditar que existem muros brancos em muitos lugares, galerias, televisão, revistas, teatro. A cidade não pára. E os adolescentes não páram de se reinventar...

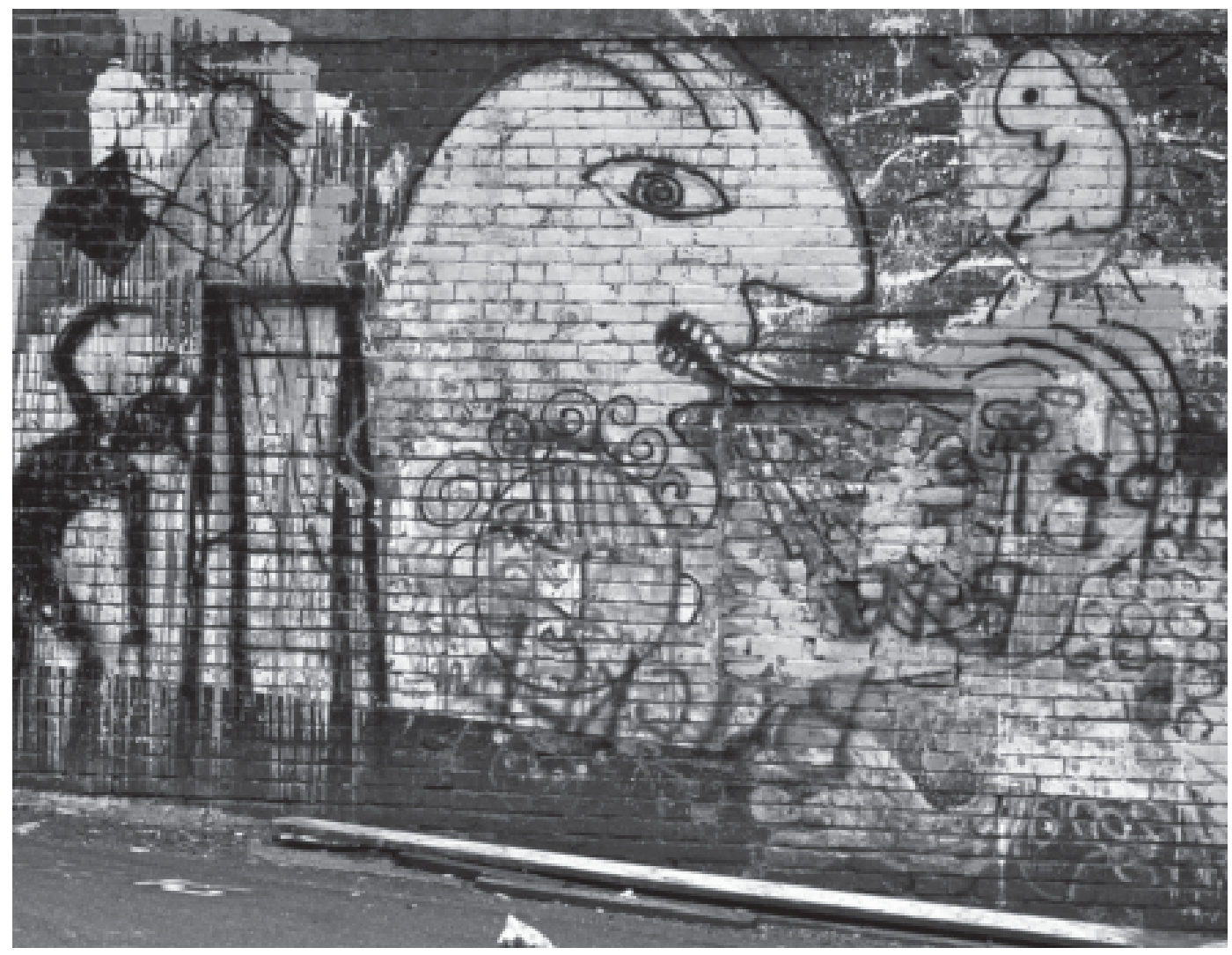


Rodrigo Lages e Silva Rua Sofia Veloso, 120/308 Cep.:90050-140 Porto Alegre/ RS E-mail:rodrigo.lages@uol.com.br

BAUDELAIRE, Charles P. Pequenos Poemas em Prosa. Rio de Janeiro: Nova Fronteira, 1976.

BAUDRILLARD, Jean. Kool Killer ou a Insurreição Pelos Signos. Extraído do site: http://www.rizoma.net ,1976.

BENJAMIN, Walter. Paris, Capital do Século XIX e a Paris do Segundo Império em Baudelaire. In Kothe, F.(org). Walter Benjamin. São Paulo: Ática, 1985.

CALLIGARIS, Contardo. Adolescência. São Paulo: Publifolha, 2000.

CERTEAU, Michael. A Invenção do Cotidiano: Artes de Fazer. Petrópolis: Vozes, 1994.

A Cultura no Plural. Campinas: Papirus, 1995.

GINZBURG, Carlo. Mitos, Emblemas e Sinais: Morfologia e História. São Paulo: Companhia das Letras, 1989.

HARENDT, Hannah. Sobre a Violência. Rio de Janeiro: RelumeDumará, 1994.

HERSCHMANN, Micael. O Funk e o Hip Hop Invadem a Cena. Rio de Janeiro: Editora UFRJ, 2000.

KERCKOVE, Derrick de. A Pele da Cultura. Lisboa: Relógio D’Água, 1997.

LEMINSKI, Paulo. APaixão da Linguagem. In Novaes, Adauto (org.). Os Sentidos da Paixão. São Paulo: Companhia das Letras, 1995.
OLALQUIAGA, Celeste. Megalópolis: Sensibilidades Culturais Contemporâneas. São Paulo: Estúdio Nobel, 1998.

Referências

PIGNATARI, Décio. Letras, Artes, Mídia. São Paulo: Editora Globo, 1995.

Paulo: Perspectiva, 1970

Informação. Comunicação. Linguagem. São

RASSIAL, Jean-Jacques. O Adolescente e o Psicanalista. Rio de Janeiro: Companhia de Freud, 1999.

A Passagem Adolescente: da Família ao Laço Social. Porto Alegre: Artes e Ofícios - 1997.

RUIZ, Manuel D. Ciudad Líquida, Ciudad Interrumpida. Medelin: Universidad Antiqua, 1999.

SORDI, Regina. A Construção Subjetiva do Conhecimento. In Renedo, Alicia. Revista da E.PSI.B.A., nº 4, 1997.

SOUSA, Janice T. P. de. Reinvenções da Utopia: a Militância Política dos Jovens. São Paulo: Hacker Editora, 1999

SOUZA, Edson L. A de. O Eu nos Textos: Escritos Adolescentes. In APPOA. Adolescência: Entre o Passado e o Futuro. Porto Alegre: Artes e Ofícios, 1997.

. O Inconsciente Entre o Escrito e o Escritor. In Revista da Appoa. Psicanálise e Literatura, $\mathbf{n}^{\mathbf{0} 15}$, Ano VIII, novembro 1998 